\title{
The Study of Google Search Trends for an Effective Communication during COVID-19 Pandemic
}

\author{
*Nayeem Showkat \\ **Mubashir Gull \\ *Assistant Professor, Department of Convergent Journalism, Central University of Kashmir. \\ Also Research Scholar, Department of Mass Communication, Aligarh Muslim University, \\ Aligarh India \\ **Post Doctoral Fellow (ICSSR), Department of Psychology, Aligarh Muslim University, \\ Aligarh India
}

\begin{abstract}
Internet could be effectively used by the media outlets for risk and outbreak communication in the current crisis. The news stories and videos must be tagged keeping the search terms of people in consideration. This audience-centric approach may be used to supply people with more credible information and guidelines time-to-time. This article analyses the keywords used by the public to search the content related to pandemic so that media outlets may produce and disseminate the related content accordingly via their digital platforms. A paired sample t-test was used to compare Google News and YouTube searches on selected keywords related to COVID-19.
\end{abstract}

Keywords: COVID-19, novel coronavirus, Google Trends, outbreak communication, pandemic 


\section{Background \& Introduction}

COVID-19 is one of the most emerging topics of research in the world now. The scientific community is yet to unveil many things about the new virus. The COVID-19 (Coronavirus infectious disease- 2019) is caused by SAR-CoV-2, a virus belonging to the family of Coronaviruses. Started from China, according to World Health Organisation (WHO) a "pneumonia of unknown cause detected in Wuhan, China was first reported to the WHO Country Office in China on $31^{\text {st }}$ December 2019." (WHO, 2020). According to South China Morning Post, as per the Chinese Government data the first Covid-19 case in China can be traced to November 17, 2019.

Virus become a global problem on $13^{\text {th }}$ January, 2020 after a case was recorded in Thailand before, South Korea and the United States (Amos, 2020). Since then the virus has been spreading like wildfire across the globe.

World Health Organisation announced COVID-19 a Public Health Emergency of International Concern on $30^{\text {th }}$ January, 2020. The virus spread so fast that within less than month-and-a-half, the WHO declared COVID-19 as a pandemic on $11^{\text {th }}$ March, 2020. Replacing Wuhan in China, Europe was declared as the new epicenter of pandemic on $13^{\text {th }}$ March, 2020 by WHO (WHO, 2020)

The pandemic has been posing a direct threat to the entire science and technology-driven society. Since there is no antidote for the treatment of novel coronavirus for now, therefore there are only some important precautionary measures to be taken by authorities and the people across the globe which are time and again communicated through news media. Among them lockdown, physical distancing, self-isolation or quarantine, testing and hand wash are important to mention. 
The COVID-19 pandemic has spread to all corners of the globe (McCarthy, 2020). With more than half-a-million cases recorded in United States till $12^{\text {th }}$ April, 2020, the virus has spread to around 185 countries in the world. United States is followed by Spain, Italy, France, Germany, China, United Kingdom, Iran and Turkey. Further, according to the data retrieved from the Johns Hopkins University \& Medicine Corona Resource Centre on $12^{\text {th }}$ April, 2020 at 12 noon (according to Indian Standard Time), India ranked 22 in the world with 8446 positive cases and 288 deaths due to novel coronavirus.

The first positive case of COVID-19 in India was recorded on $30^{\text {th }}$ January, 2020 in Kerala (The Economics Times, 2020). According to government data retrieved on $12^{\text {th }}$ April at 11:40 A.M. Maharashtra leads in India with 1574 cases followed by Delhi with 903 cases of COVID19. Nagaland is the only state in India where no case has been recorded so far ("Government of India", 2020). India has put in place many measures like lockdown, physical distancing measures and others to contain the spread of virus. Indian government announced a 21-day nationwide lockdown on $25^{\text {th }}$ March, 2020. The lockdown was further extended for more than two weeks till $3^{\text {rd }}$ May, 2020(The Indian Express, 2020). Despite taking all these majors across globe, the cases of novel coronavirus are intensifying each passing day.

\section{Importance of Risk and Outbreak Communication}

In view of absence of any antidote, the only and the most effective tool available with the authorities to contain the spread of virus is building trust for risk and outbreak communication. On the other side, apart from the direct threat of death, the virus has been posing an indirect threat to structure of the society. For example; according to the WHO, "social distancing" (actually "physical distancing") remains prevalent construct to contain the spread of virus(WHO, 2020). The sociological question is what it actually means by "social distancing". The misunderstanding of the idea of "social distancing" the way it seems to have been used may lead the world to the worst. In social psychology, "social distancing" has negative connotations.

In sociological perspective, the indirect threat is invisible but more grave challenging the whole idea of a society. The sociological problem is that humans have started spying each other as possible threat and carrier of virus and have started generalizing all the humans as Covidiots (a person who ignores the warnings regarding public health and safety). 
Meanwhile, the other major problems faced by the authorities are that people have not been obeying the orders of lockdown and physical distancing strictly. As is evident from the research, public in major parts of the world is finding it very difficult to change its behviour towards accepting the new norms of lockdown, physical distancing and quarantine(Kumar, 2020).

Further, people have been concealing the travel history may be due to a trust deficit. Nothing but strategic communication may help in bridging this trust deficit, and effectively and consistently update the people about the do's and don'ts during the pandemic. Media plays an important role in information dissemination, social mobilisation and behavioural changes (UNICEF, 2005). The body of literature, according to its agenda setting function, suggests that media have a significant if not unlimited effect on the attitudes and behaviour of the audiences. (Neuman and Gugeheim 2009). As per the function of media is concerned according to this central theory of media effects, it becomes cardinal for media to produce and disseminate the digital content which could be successful in behavioural changes of the people related to the pandemic. It is media's responsibility to give utmost importance to the outbreak communication. The media has to provide significant time and space to the emerging health crisis. It has to prime the novel coronavirus news and repeat the same (McCombs\& Shaw, 1972).

We also assume that audiences in pandemic have been playing an active role in searching and reading the news content related to novel coronavirus. The study uses a bottom-up approach to understand how audiences are searching for particular information related to novel coronavirus. The article uses a audiences-centric approach for determining an agenda to be set by the media accordingly during the pandemic. The study evaluates how people are searching so that media could produce more news and videos using the same keywords which would be easily available and accessible digitally to the people across the globe.

History is evident that effective communication proved to be instrumental in containing the major risks posed to the society over time. The information dissemination to educate the public majorly depends on channels and methods of dissemination. (Crisis and Emergency Risk Communication: Communication Plan Implementation for a Sever Pandemic, (n.d.).

Pandemic has also effected printing and circulation of the newspapers in many parts of the world. Many newspapers across the globe have already stopped printing the hardcopies of their publications or editions. Many important newspapers have also stopped door-to-door delivery 
of the newspaper across globe(Waterson, 2020). In such a case, the channels of information already have shrink due to the pandemic. In this regard, a new strategy to reach the public becomes imperative.

Using Thomas Abraham's (2011) tool of "understanding and effectively using Internet" for risk and outbreak communication, this article analyses the Google Trends for a better understating of people's search interest. The article analyses the most searched keywords related to the pandemic in the last four months beginning $17^{\text {th }}$ November, 2019 to $10^{\text {th }}$ April, 2020. $17^{\text {th }}$ November, 2019 was treated as initial date as the first case in China is said to have been recorded on the same day(Ma, 2020).

Internet is an effective medium for transmitting the message to the public. It is an important channel connecting the communicators with audiences and vice-versa (Thomas Abraham, 2011).Web provides an 'alternate lines of knowledge' circulation where websites and blogs also challenged assessments by experts and authorities(Briggs \& Nichter, 2009). The magnitude of a pandemic majorly depends on effectiveness of health risk communications(Vaughan \& Tinker, 2009).Strategic communication is vital for behaviour change and trust building during a pandemic. The goals of communication during a pandemic should be "simple, straightforward and realistic". The responses and messages should be timely, relevant, accurate, credible, consistent, honest and appropriate, regular and relevant(Crisis and Emergency Risk Communication: Communication Plan Implementation for a Sever Pandemic, (n.d.).

\section{Significance of the Study}

Google News Trends have emerged as an importance source of information to study people's media usage behviour. The Google Trends also enables researchers to study users' information and health education needs. At the time of epidemics and pandemics, the audiences' information needs to gratify their requirements directly or indirectly can play an important role in containing the threats posed by the outbreaks.

What could be termed as cardinal during the outbreaks, Google Trends provides an opportunity to the authorities to understand the information needs of masses quickly and act accordingly.At a time when physical distancing is much needed, virtual networks and information through Internet plays an important role for a better informed public.

Keeping in view the above literature about the importance of mass media in informing the people through Internet about the pandemics, the study analyses the current trends and 
keywords followed and searched by the people related to the current pandemic across the globe in general and India in particular. The study would help to analyse the tags and keywords, the online platforms across the world can use to optimize the search terms of their articles, news stories, videos and other content related to the novel coronavirus via search engines like Google and YouTube. The article would further help for a better understating of tags, keywords and SEOs for keeping the information related to the current pandemic readily available for the public via online platforms.

Optimization of all the communication tools and channels as per the search terms of netzines will be helpful in achieving the communication goals during the current pandemic. The Google Trends will be significant in revealing the effective usage of Internet to reach the people timely and provide people with health education.

Findings of the study will help to develop a broader understanding of people's perception as per their search terms about the current pandemic are concerned. This article analyses the keywords used by the public to search the content related to pandemic so that media outlets may produce and disseminate the related content accordingly via their digital platforms.

Such an attempt will be helpful for mass media, policy makers and facilitators to understand the information and education needs of public in a better way so that much needed social and behavioural changes are attained. The need to relook into the communication strategy of mass media to contain the pandemic is paramount.

This article will also help us to understand the current popular medium and tool used by the people to gratify their needs of health education in this time of crisis. It will help us to answer the questions related to people's choice that whether they are more likely interested in consuming textual information or visuals about the current global health crisis. The analysis of Google Trends will help mass media to produce the messages related to the outbreak accordingly.

\section{Methodology}

A series of news articles trending on news.google.com from different sources related to COVID-19 were downloaded. Out of a total of 30 news articles published digitally by major international news organisations across the globe, a list of 20 keywords related to novel coronavirus used in the news articles were selected with the help of content analysis.

The content validity of these keywords was further checked by six experts working in the field of virology, psychology, mass communication, and medicine. All the experts were approached 
to rate these keywords for the relevance of the current situation. After analysis, seven keywords were discarded based on the experts' recommendation.

Hence, a total of 13 keywords related to COVID-19 were finally shortlisted by the authors. The keywords are as follows; Coronavirus, Lockdown, Quarantine, Social Distancing, Hand wash, Outbreak, Epidemic, Pandemic, Sanitizer, COVID 19, Coronavirus Testing, N95 mask and Novel Coronavirus.

\section{Data source}

Google Trends (https://trends.google.com/trends/explore $\# \mathrm{cmpt}=\mathrm{q}$ ) have been used to collect the data. It shows how often search terms are entered in Google relative to the total search volume in a region as well as globally. The search term was delimited to the period and web search. The period for this study was selected from $17^{\text {th }}$ November, 2019 to $10^{\text {th }}$ April, 2020. The search terms were delimited to the Google News and YouTube searches. The data was collected from two geographical locations only - Worldwide and India.

\section{Statistics}

An appropriate statistic like mean, standard deviation, paired sample t-test, and line graphs were used to analyze the data. The data was analyzed through SPSS (Statistical Package for Social Sciences). A paired sample t-test was used to compare the mean difference between Google News and YouTube search on the keywords. A line graph was used to visualize the trend over the period of time.

\section{Results and Interpretation}

Initially, the aforementioned 13 keywords were used to analyse the global trend in order to understand audiences' preference in consuming the media messages related to novel coronavirus across the world.

Table 1 compares mean score of the Google News and YouTube searchers on the aforementioned 13 keywords - Coronavirus, Lockdown, Quarantine, Social Distancing, Hand wash, Outbreak, Epidemic, Pandemic, Sanitizer, COVID 19, Testing, N95 mask and Novel Coronavirus across the world. The analysis of data reveals a significant difference at .05 level of confidence between Google News and YouTube on "coronavirus", "lockdown", "social distancing", "hand wash", “epidemic", "pandemic”, "sanitizer", “COVID 19”, “coronavirus testing", "N95 masks" and "novel coronavirus". The mean score of YouTube searches is higher as compared to Google News searches on all keywords except "coronavirus", 
"sanitizer," "COVID 19" and "coronavirus testing". These four mentioned search terms record a higher mean on Google News.

After analysing the world trend, Google Trends in India were analysed as whole, further followed by a state-wise analysis.

Table 1shows mean difference between Google News and YouTube on selected keywords across the world (World trend)

\begin{tabular}{lllccccc}
\hline & Keywords & & & Statistics & $\mathrm{df}$ & $\mathrm{p}$ & $\begin{array}{c}\text { Mean } \\
\text { difference }\end{array}$ \\
\hline 1 & Coronavirus & Google News & YouTube & 5.322 & 117.0 & $<.001$ & 5.322 \\
2 & Lockdown & Google News & YouTube & -4.106 & 145.0 & $<.001$ & -3.767 \\
3 & Quarantine & Google News & YouTube & -1.757 & 145.0 & 0.081 & -2.836 \\
4 & Social Distancing & Google News & YouTube & -4.114 & 145.0 & $<.001$ & -4.411 \\
5 & Hand wash & Google News & YouTube & -6.667 & 145.0 & $<.001$ & -14.370 \\
6 & Outbreak & Google News & YouTube & -0.377 & 145.0 & 0.707 & -0.473 \\
7 & Epidemic & Google News & YouTube & -12.638 & 145.0 & $<.001$ & -24.164 \\
8 & Pandemic & Google News & YouTube & -3.640 & 145.0 & $<.001$ & -6.384 \\
9 & Sanitizer & Google News & YouTube & 3.984 & 99.0 & $<.001$ & 7.230 \\
10 & COVID 19 & Google News & YouTube & 5.972 & 144.0 & $<.001$ & 2.531 \\
11 & Coronavirus Testing & Google News & YouTube & 2.801 & 145.0 & 0.006 & 3.377 \\
12 & N95 mask & Google News & YouTube & -2.259 & 145.0 & 0.025 & -3.260 \\
13 & Novel Coronavirus & Google News & YouTube & -3.72 & 145.0 & $<.001$ & -5.520 \\
\hline
\end{tabular}

Table 2 shows mean difference between Google News and YouTube on selected keywords across the India (India trend)

\begin{tabular}{|c|c|c|c|c|c|c|c|}
\hline & Keywords & & & Statistics & df & $\mathrm{p}$ & $\begin{array}{c}\text { Mean } \\
\text { difference }\end{array}$ \\
\hline 1 & Coronavirus & Google News & YouTube & 8.029 & 144 & $<.001$ & 9.938 \\
\hline 2 & Lockdown & Google News & YouTube & -1.206 & 145 & 0.230 & -1.397 \\
\hline 3 & Quarantine & Google News & YouTube & 5.081 & 145 & $<.001$ & 7.527 \\
\hline 4 & Social Distancing & Google News & YouTube & 2.584 & 145 & 0.011 & 4.288 \\
\hline 5 & Hand wash & Google News & YouTube & -8.599 & 145 & $<.001$ & -15.329 \\
\hline 6 & Outbreak & Google News & YouTube & -1.136 & 145 & 0.258 & -2.651 \\
\hline 7 & Epidemic & Google News & YouTube & -3.060 & 145 & 0.003 & -7.151 \\
\hline 8 & Pandemic & Google News & YouTube & 0.656 & 145 & 0.513 & 1.212 \\
\hline 9 & Sanitizer & Google News & YouTube & 0.410 & 145 & 0.683 & 0.507 \\
\hline 10 & COVID 19 & Google News & YouTube & 1.524 & 145 & 0.130 & 0.925 \\
\hline 11 & Coronavirus Testing & Google News & YouTube & 2.440 & 145 & 0.016 & 3.842 \\
\hline 12 & N95 mask & Google News & YouTube & -0.337 & 145 & 0.736 & -0.541 \\
\hline 13 & Novel Coronavirus & Google News & YouTube & 0.912 & 145.0 & 0.365 & 1.590 \\
\hline
\end{tabular}


Table 2 compares the mean score of the Google News and YouTube searchers on the aforementioned 13 keywords- Coronavirus, Lockdown, Quarantine, Social Distancing, Hand wash, Outbreak, Epidemic, Pandemic, Sanitizer, COVID 19, Coronavirus Testing, N95 mask and Novel Coronavirus. The analysis of data reveals a significant difference at .05 level of confidence between Google News and YouTube on "coronavirus", "quarantine", "social distancing", "hand wash", "epidemic", and "coronavirus testing". The mean score of Google News is higher than YouTube searches on "coronavirus", "quarantine", "social distancing" and "coronavirus testing”. Whereas, YouTube searches are higher as compared to Google News on "hand wash" and "epidemics". It can be stated that people search more content and media messages related to these keywords on Google News and YouTube respectively. However, on the other side, a statistically insignificant difference was found between the two search engines on "lockdown”, “outbreak", “pandemic”, “sanitizer”, "COVID 19”, "N95 masks”, and" novel coronavirus". The findings reveal that people are searching both for videos and news stories about the "lockdown”, “outbreak", "pandemic", "sanitizer", “COVID 19' and "N95 mask".

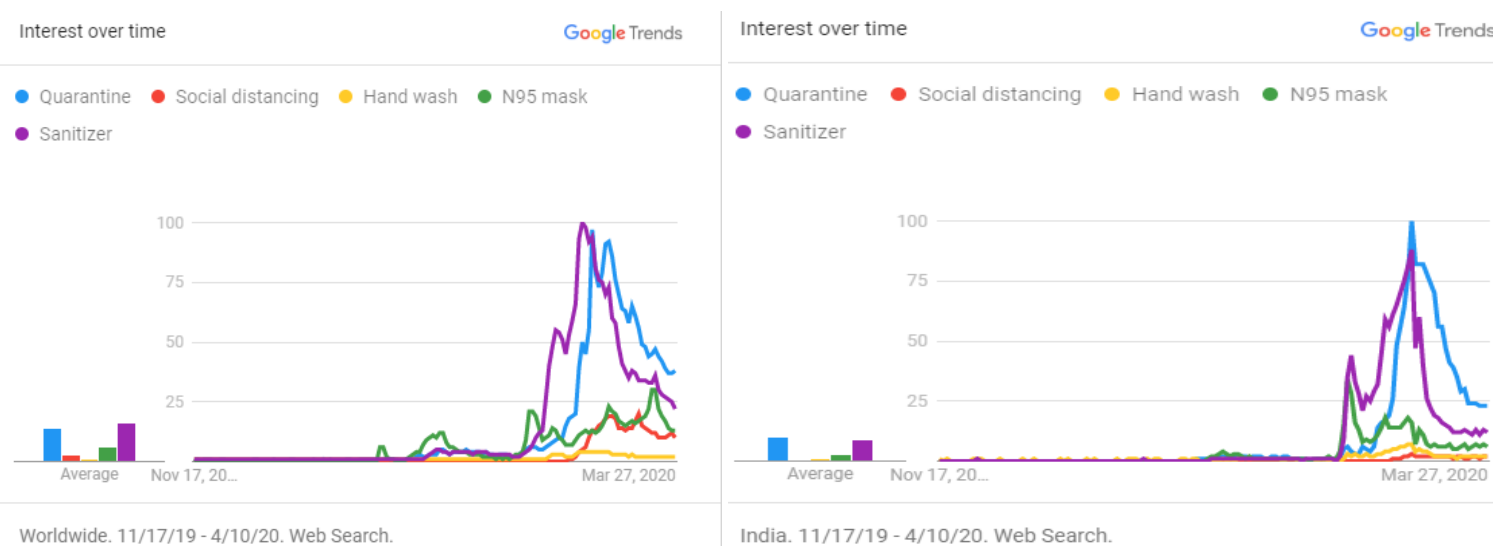




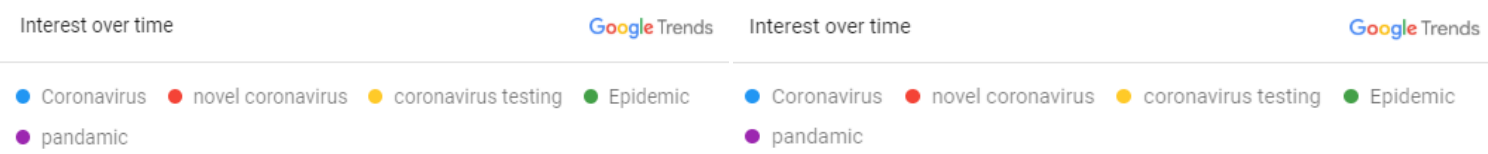

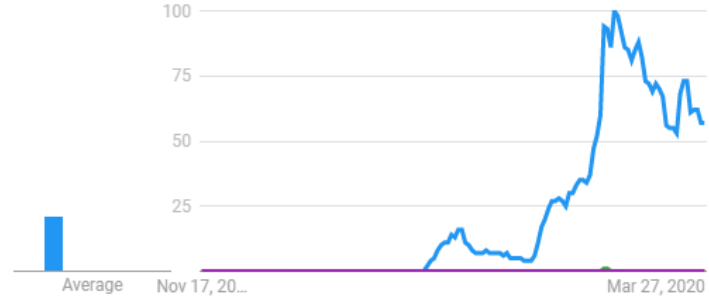

Worldwide. 11/17/19-4/10/20. Web Search.

Interest over time

- Covid 19 - Outbreak - Lockdown

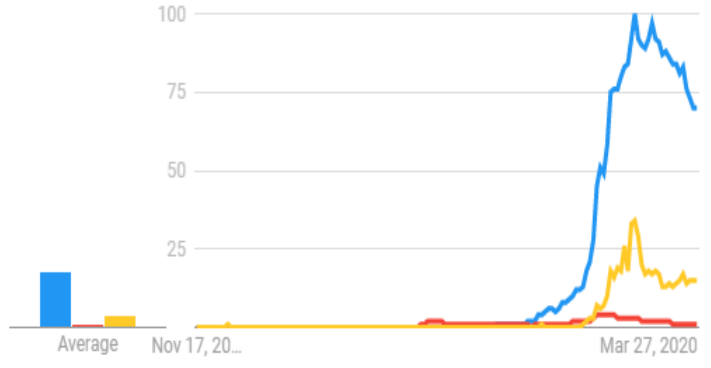

Worldwide. 11/17/19-4/10/20. Web Search.

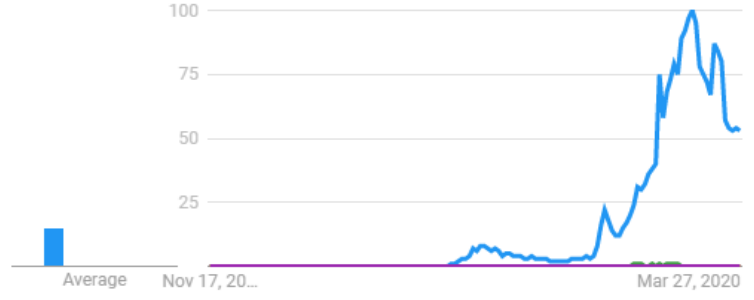

India. 11/17/19-4/10/20. Web Search.

Interest over time

Google Trends

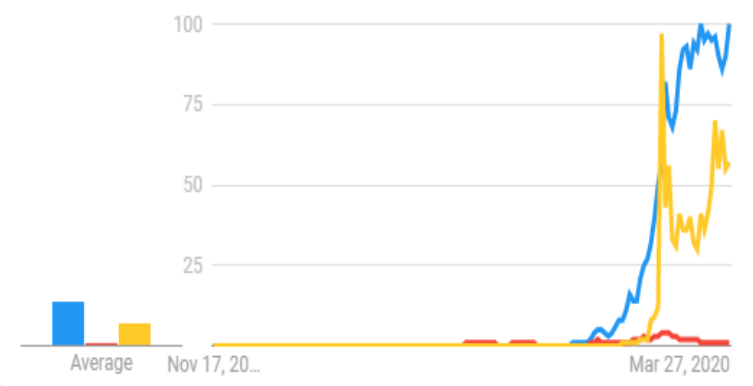

India. 11/17/19-4/10/20. Web Search.

In Google Trends only five keywords could be compared with each other at a time. Keeping in view the limitations of Google Trends, an attempt was made to categories the selected 13 keywords into three different groups namely Group 1, Group 2 and Group 3. The group were created that so that keywords could be compared with each other.

Group 1 includes "Quarantine", "Social Distancing", "Hand wash", "N95 Mask" and "Sanitizer". "Coronavirus", "Novel Coronavirus", "Epidemic", "Coronavirus testing" and "Pandemic" were listed in Group 2. Whereas Group 3 includes "Outbreak", "Lockdown" and "COVID 19".

The keywords listed in Group 1 when compared with each other, it was found that "sanitizer" and "quarantine" were the most searched keywords both in India and across the world. Among the keywords in Group 2, "coronavirus" was found to have been most searched in India and 
across the world. "COVID 19" followed by "lockdown" were found to have been highest searched keywords in India and across the world in Group 3. 
Mean of date-wise search of keywords across India
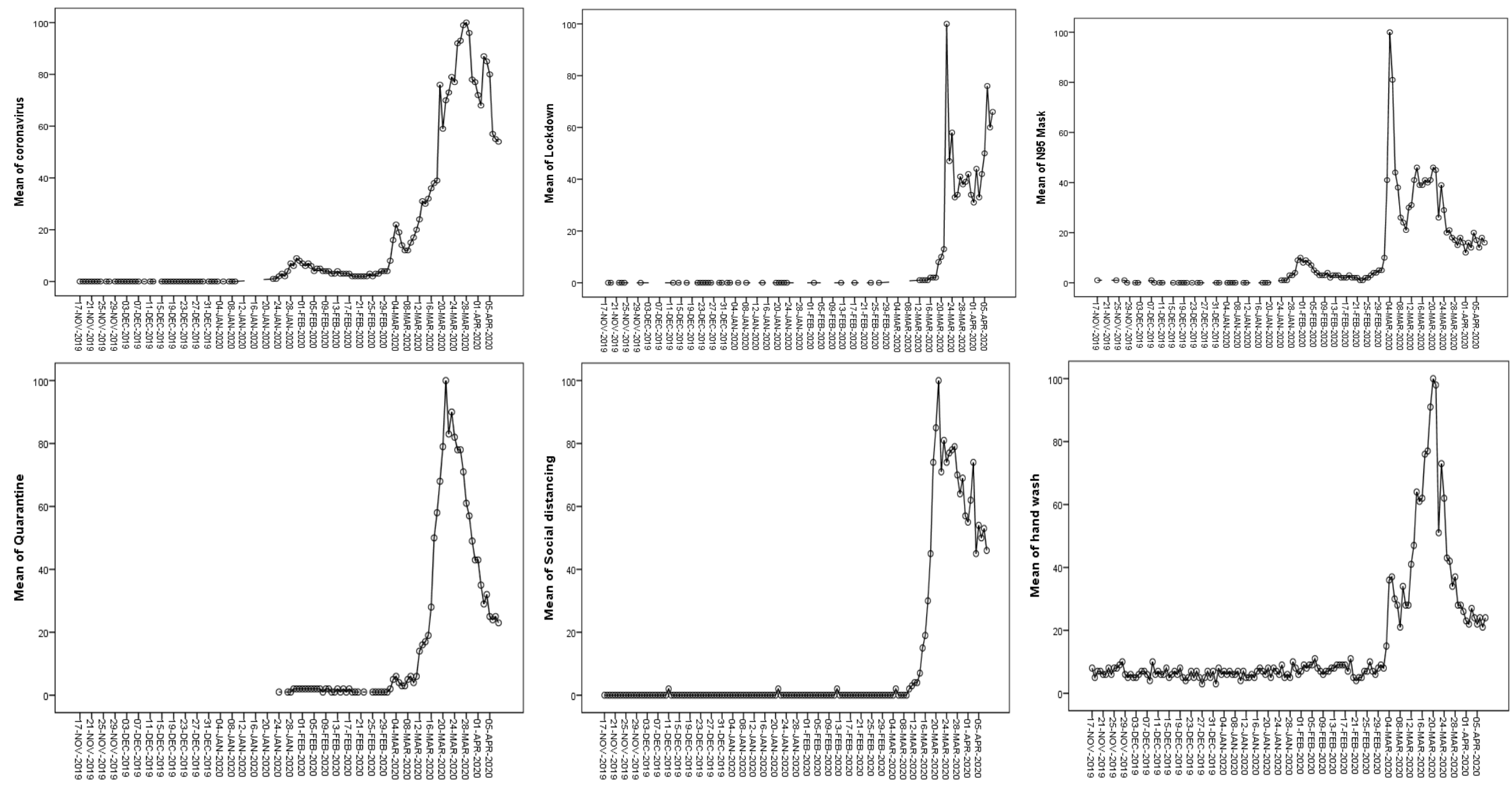

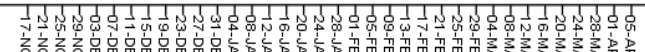

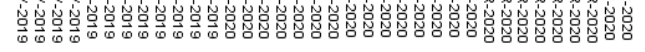




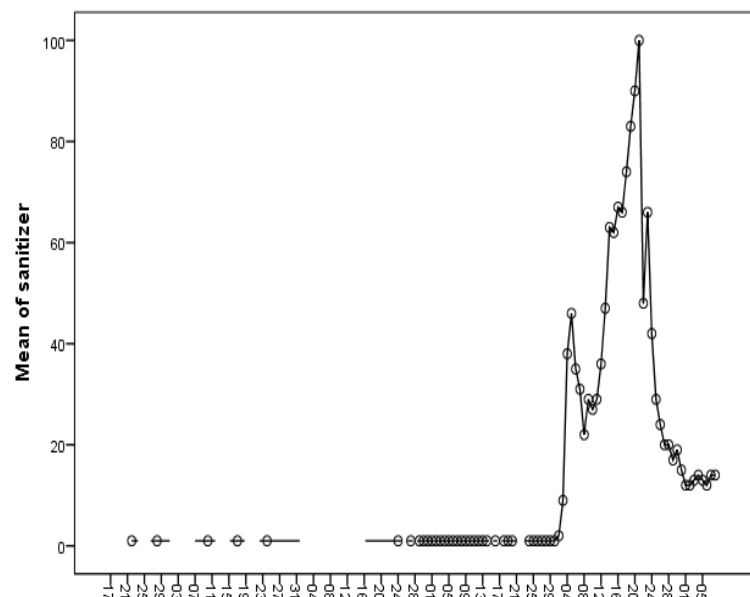

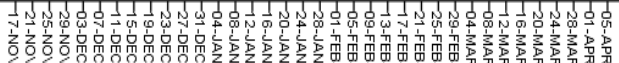

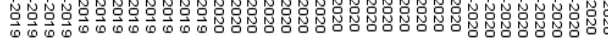

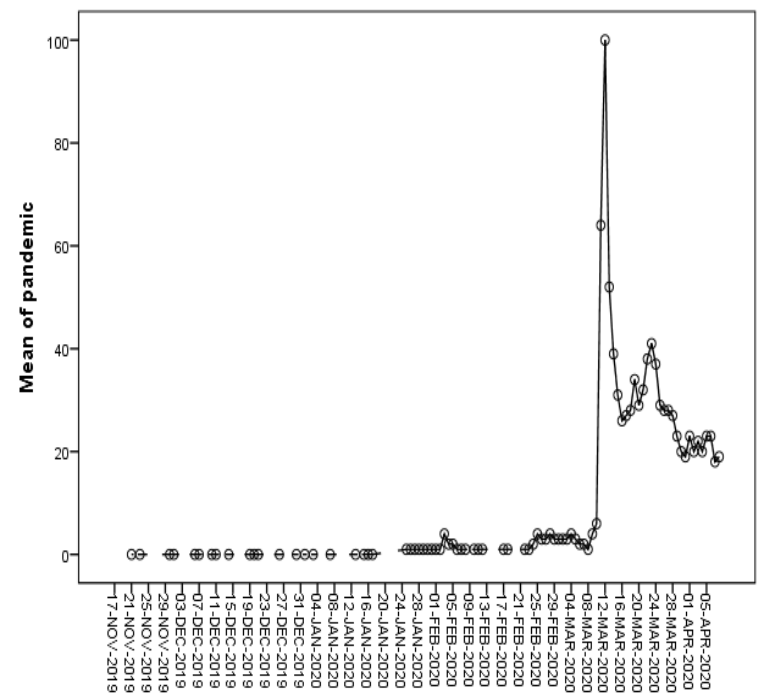

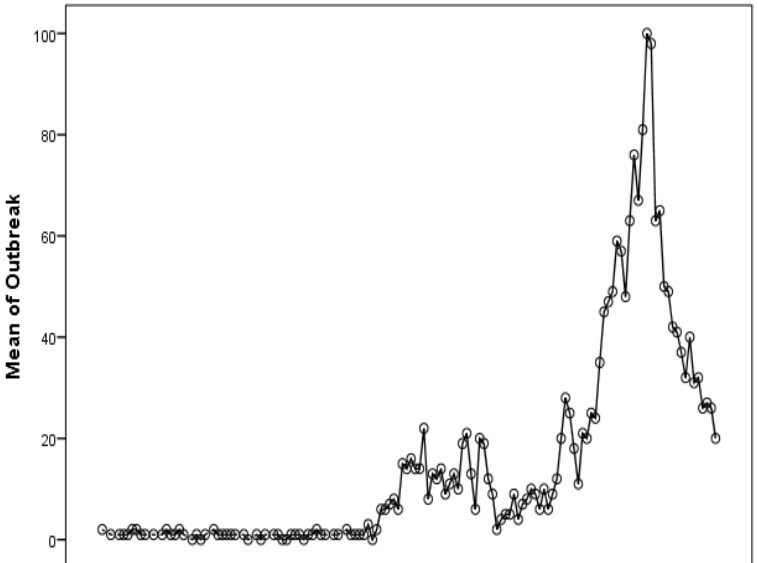

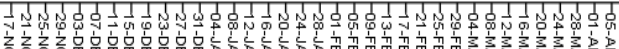

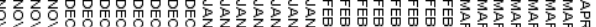

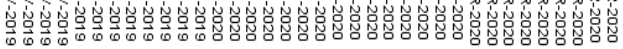

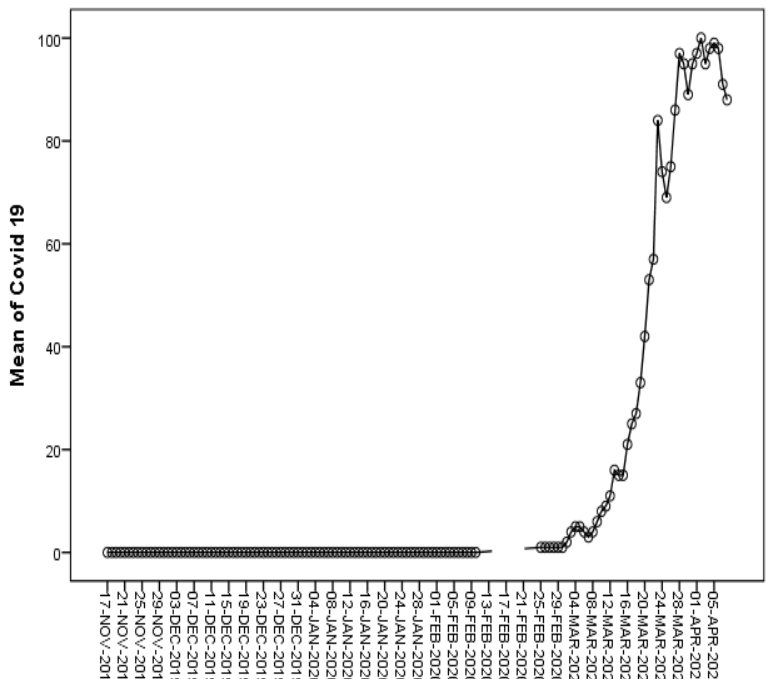

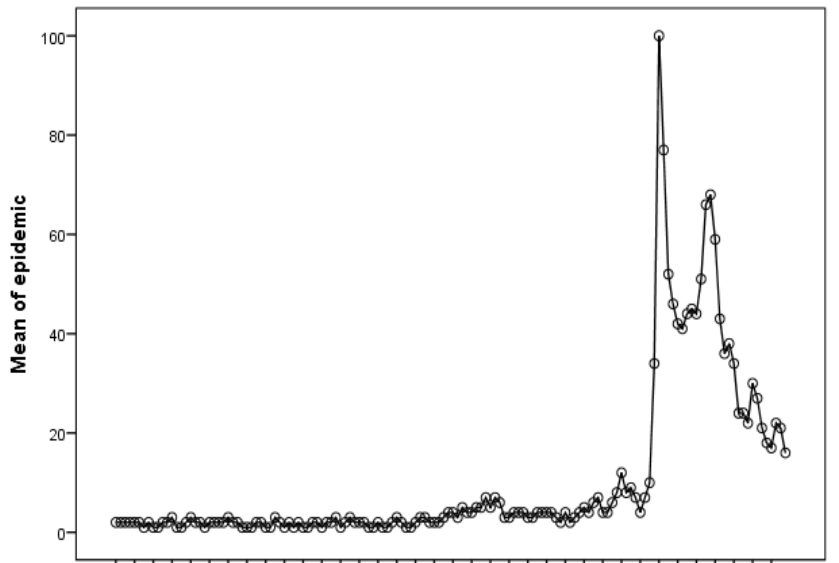

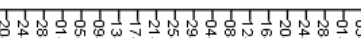

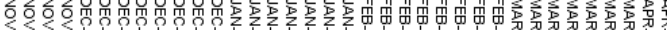

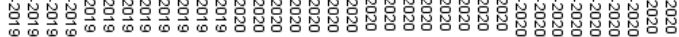

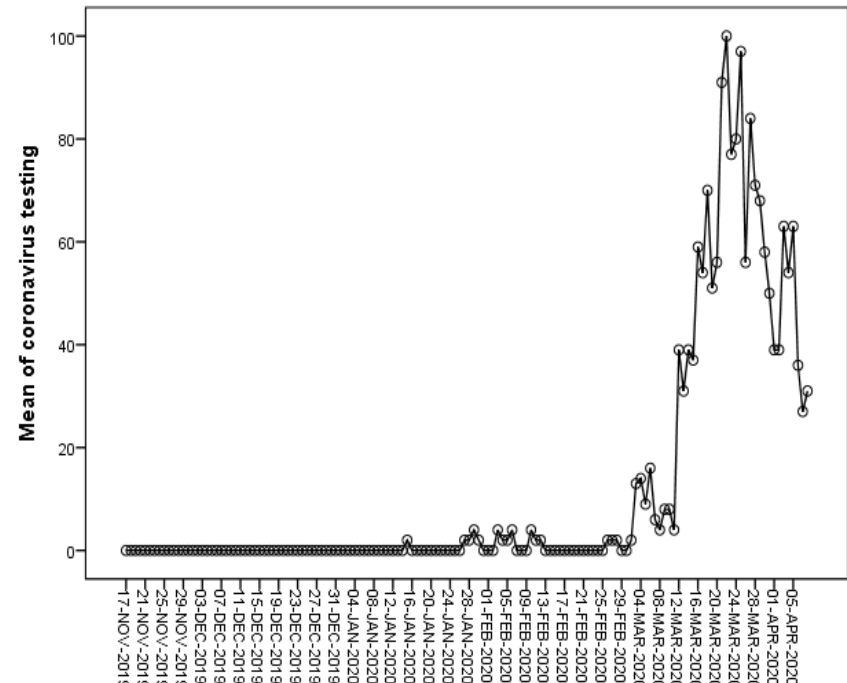


Line graph was used to exhibit the number of searches over the period. The X-axis represents the number of searches related to keywords from $17^{\text {th }}$ November, 2019 to $9^{\text {th }}$ April 2020. Whereas, Y-axis represents the number of days.

The above line graphs reveal that the search for keywords like "coronavirus" and "outbreak" in India was started between the last week of January, 2020 and the beginning of first week of February, 2020.This was the time when coronavirus was reported in India from Kerala on $30^{\text {th }}$ January, 2020.

However, the searches about the keywords like "lockdown", "quarantine", "social distancing", "hand wash", "sanitizer", “epidemic", "pandemic", "COVID 19”, “coronavirus testing” and "N95 mask" recorded a rise since the early March, 2020. Further, the search terms for these keywords recorded a significant increase in month of April, 2020. 
Mean of state-wise search of keywords across India
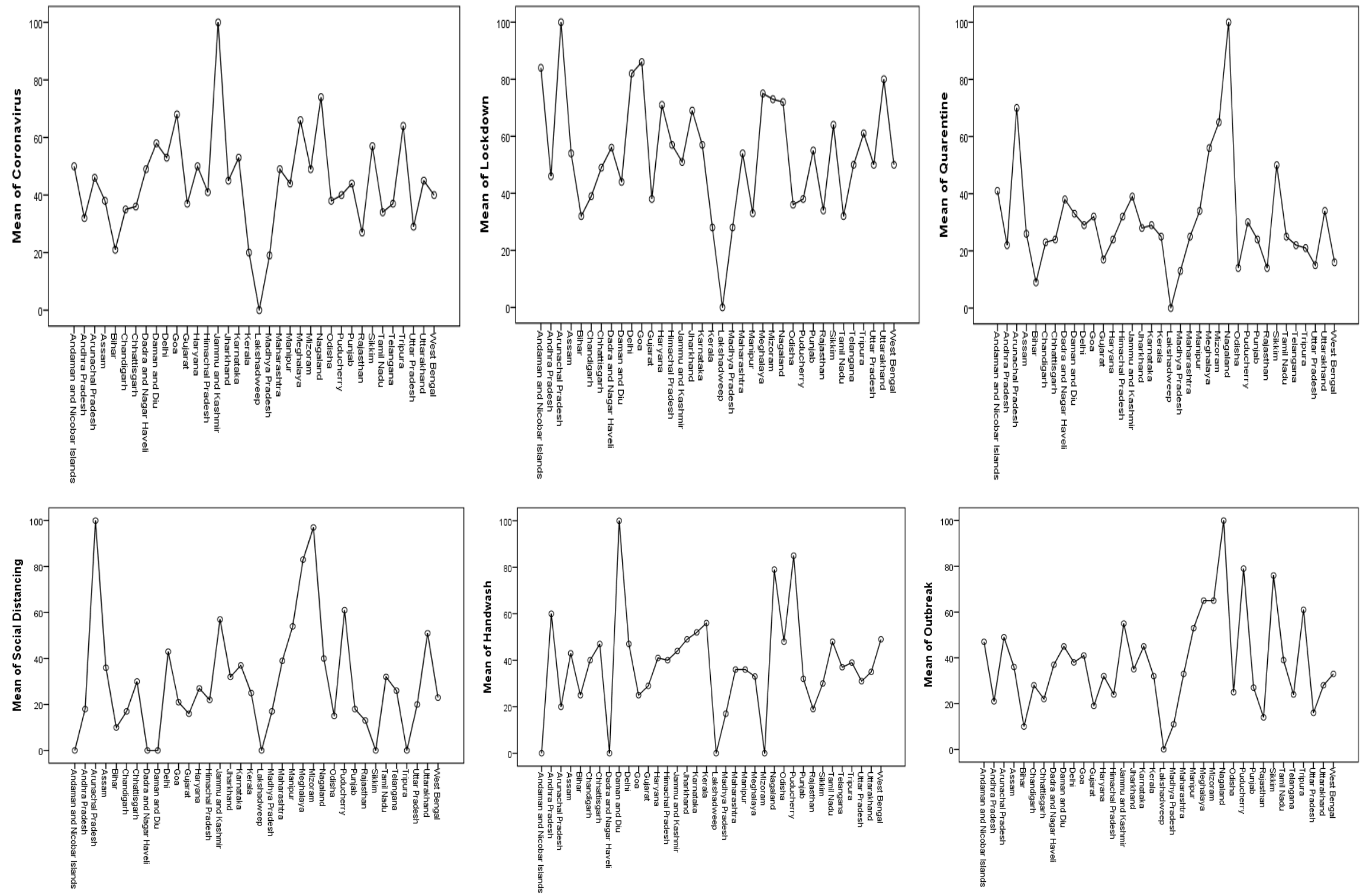

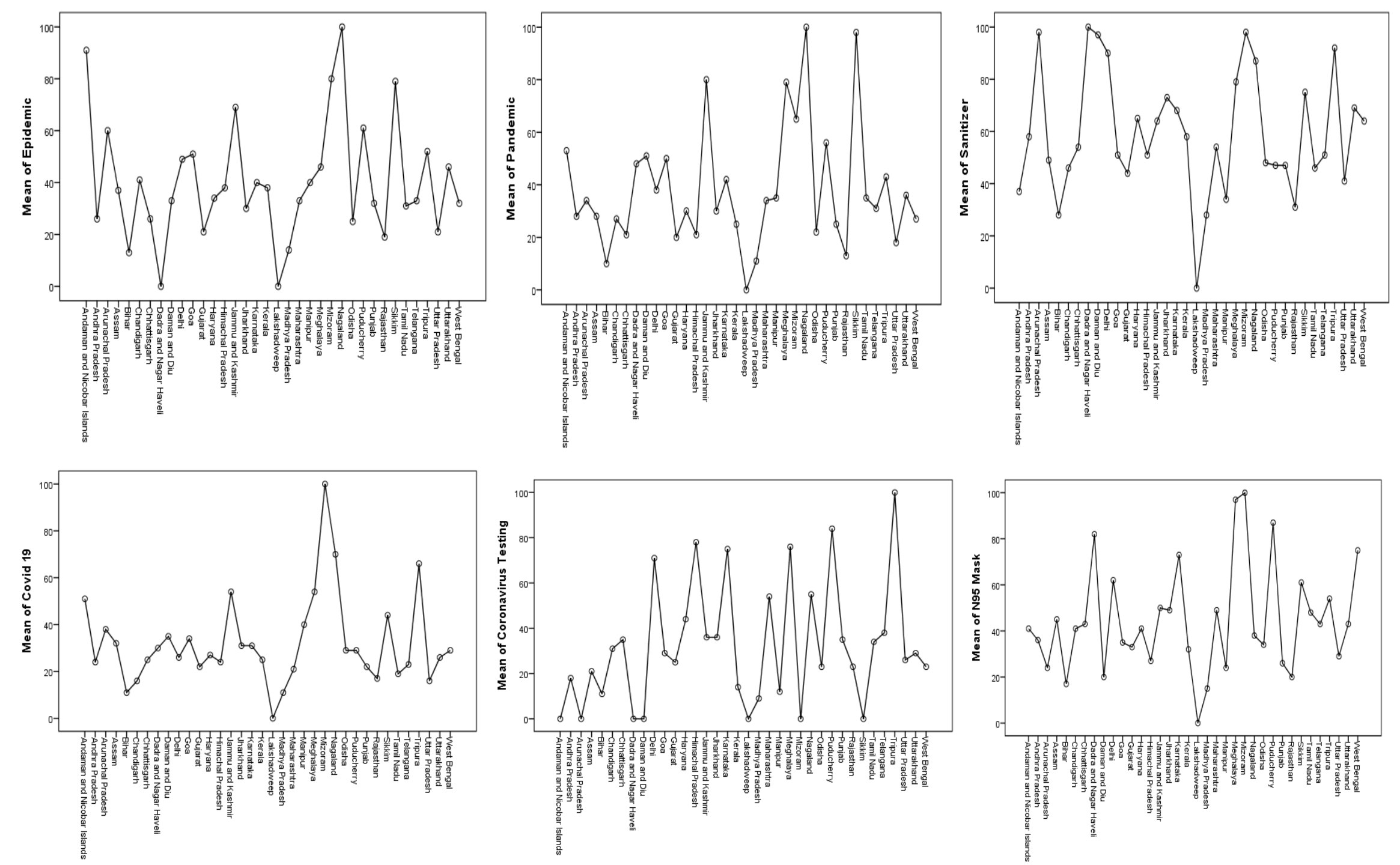


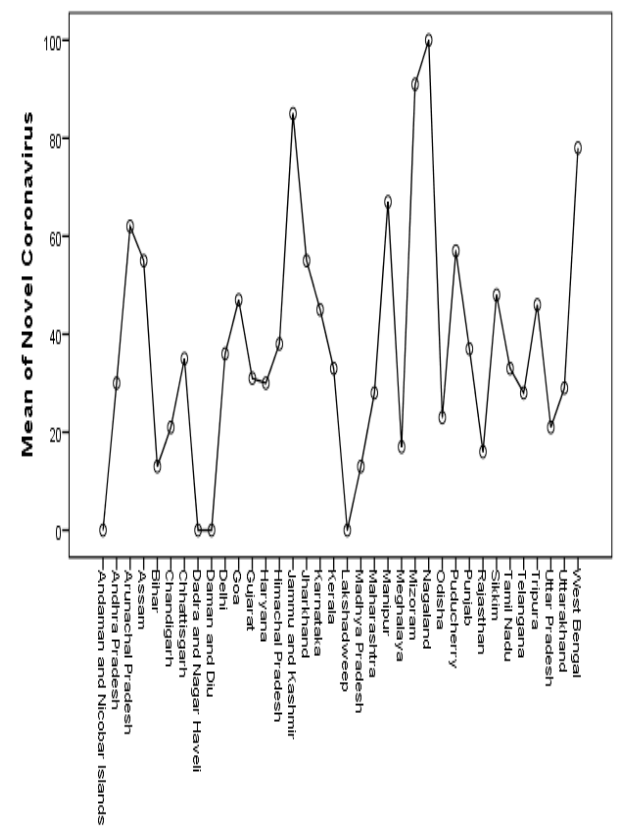

To take a deeper look into the search trends in India, the Google Trends' data was further organised and analysed state-wise. The line graph has been used to display the same. Findings reveal that Jammu and Kashmir records highest searches about the "coronavirus" followed by Nagaland and Delhi. Among all the states and union territories, Lakshadweep and Bihar record least searches about the "coronavirus". The reason behind the Lakshadweep's low score may be its comparatively less population.

Result indicates that the people of Jammu and Kashmir and Nagaland seem to be more conscious/interested to know about the causes and consequences of the virus. Nagaland followed by Puducherry also records highest searches for the keyword "outbreak". Besides "coronavirus", the people in Delhi are more interested in keywords "hand wash" and "coronavirus testing".

The keyword "quarantine", "pandemic" and "epidemic" were most searched in Nagaland. Nagaland was followed by Sikkim, Jammu and Kashmir, Arunachal Pradesh, and Daman and Diu respectively on "pandemic" and "epidemic". "Quarantine" was least searched in Andhra Pradesh. In the same way, the people in Lakshadweep, Bihar and Rajasthan were least interested in searching "pandemic" and "epidemic".

Again, "sanitizer" and "COVID 19" related searches were highest from the Nagaland, Arunachal Pradesh, and Daman and Diu. Whereas Lakshadweep, Bihar and Madhya Pradesh recorded least number of searches about "sanitizer" and "COVID 19".

"Coronavirus testing" was mostly searched in Tripura, Puducherry, Himachal Pradesh, Delhi and Jammu \& Kashmir. The search terms related to "N95 mask" were mainly recorded in 
Nagaland, Mizoram and Daman and Dui. Whereas the people in Lakshadweep, Madhya Pradesh, Bihar, and Sikkim has least searched "N95 mask". The keyword "novel coronavirus" was searched majorly in Nagaland, Mizoram and Jharkhand.

\section{Discussion and Suggestions}

Google Trends reveal that there has been a significant increase in the search terms related to COVID-19 across the world. It is also evident from the result that trend for searching the Google News is significantly higher as compared to the YouTube search about COVID-19 in India.

It may be well established that people prefer Google News over YouTube for information and news related to novel coronavirus. Among all the 13 keywords, it was found that "sanitizer" "coronavirus" "COVID 19" and "lockdown" were the most searched keywords both in India and across the world. It becomes paramount for media outlets to produce media messages using these four most searched key terms for further mass dissemination.

Overall in India, Google Trends show that keywords related to coronavirus have been mostly searched in states likes Nagaland, Dadra and Nagar Haveli and Mizoram. It is important to mention that these states have recorded fewer cases of COVID-19. The keyword "coronavirus" itself was most searched from Jammu and Kashmir.

Therefore, it can be said that there is a relationship between the Google Trend searches and number of cases of novel coronavirus. With few exceptions, the findings reveal that states where most searches related to the current pandemic have been registered, only few cases of novel coronavirus have been recorded at those places. The findings suggest that people searching news and information related to COVID-19 may likely take the precautionary measures as advocated through the media messages.

The findings of the study suggest that new media can play an important role by producing more messages using the keywords studied during the course of research. The mass media could play a vital role in changing the behaviour and informing the people about this disease. The authors through this article encourages the editors of the news media and experts working in the field 
to write news stories and articles with respect to keywords like Coronavirus, Lockdown, Quarantine, Social Distancing, Hand wash, Outbreak, Epidemic, Pandemic, Sanitizer, COVID 19, Coronavirus Testing and N95 mask as much as possible.

These keywords should be used frequently in the news articles and headlines to make them easily searchable and trending on news.google.com. It is suggested that experts and groups working on this issues should also optimise their information with search engines using these frequently used keywords. The editors should timely prefer the stories using these keywords as much as possible in order to update the public about this pandemic. The rumours and myths about the virus produced using such keywords may also be removed from the web at the earliest.

The study also listed (Appendix I) the other search terms related to selected keywords for a better understanding of the masses' preferences. From the analysis, we can suggest that the media outlets at national, regional and state-level in India should understand the search terms of people of their place and produce more information using those keywords accordingly. Media both national as well as state level can set an agenda according to the search terms of the country, city and state.

Internet could be effectively used by the media outlets for risk and outbreak communication in the current crisis after understating the philosophy of search terms of the people under study. The news stories and videos must be tagged keeping the search terms of people in consideration. This audience-centric approach may be used to supply people with more credible information and guidelines time-to-time. 


\section{References}

Abraham, T. (2011). Lessons from the pandemic: The need for new tools for risk and outbreak communication. Emerging Health Threats Journal, 4, 7160. https://doi.org/10.3402/ehtj.v4i0.7160

Amos, O. (2020, March 4). Coronavirus: Where will be the last place to catch Covid-19? BBC News. https://www.bbc.com/news/world-52120439.

BBC. (2020, April 11). India "to extend" nationwide coronavirus lockdown. Available at https://www.bbc.com/news/world-asia-india-52255011.

Briggs, C. L., \& Nichter, M. (2009). Biocommunicability and the biopolitics of pandemic threats. Medical Anthropology, 28(3), 189-198. https://doi.org/10.1080/01459740903070410.

Crisis and Emergency Risk Communication: Communication Plan Implementation for a Sever $\begin{array}{llll}\text { Pandemic. } & \text { (n.d.) available at }\end{array}$ https://www.paho.org/disasters/index.php?option=com docman\&view=download\&cate gory slug=tools\&alias $=540$-pandinflu-leadershipduring-tool$\underline{13 \& \text { Itemid }=1179 \& \text { lang }=\text { en }}$

Government of India. (2020, March 28). MyGov.In. COVID19 statewise status. Available at https://mygov.in/corona-data/covid19-statewise-status/

Johns Hopkins University \& Medicine Corona Resource Centre (2020, April, 12). Available at https://coronavirus.jhu.edu/map.html.

Kumar, R. (2020, March 24). Follow Coronavirus Lockdown Rules, Else Will Have to Give "Shoot-at-sight" Order: Telangana CM - News18. News 18 India. https://www.news18.com/news/india/follow-coronavirus-lockdown-rules-else-willhave-to-give-shoot-at-sight-order-telangana-cm-2549765.html

Ma, J. (2020, March 13). Coronavirus: China's first confirmed Covid-19 case traced back to \begin{tabular}{ll|lll} 
November & 17 & South China Morning Post.
\end{tabular} https://www.scmp.com/news/china/society/article/3074991/coronavirus-chinas-firstconfirmed-covid-19-case-traced-back

McCarthy, N. (2020, August, 4). • Chart: Which Countries Have Escaped The Coronavirus So Far? | Statista. Https:/Www.Statista.Com/. https://www.statista.com/chart/21279/countries-that-have-not-reported-coronaviruscases/ 
Neuman, W. and Gugeheim, L. (2009). The evolution of media effects theory: fifty years of cumulative research. The annual meeting of the international communication association, Marriott/Chicago: IL Online, 2009.

The Economics Times (2020, April, 13). Coronavirus cases in India: State-wise break up of confirmed coronavirus Available at https://economictimes.indiatimes.com/news/politics-and-nation/coronavirus-crisisheres-total-number-of-confirmed-cases-in-india-as-per-healthministry/articleshow/74589499.cms.

The Indian Express. (2020, April, 14). Coronavirus India LIVE UPDATES: Amit Shah says stocks adequate as India extends lockdown till May 3. Available at https://indianexpress.com/article/india/coronavirus-india-lockdown-live-updates-pmnarendra-modi-speech-today-live-news-covid-19-tracker-india-cases-latest-updates$6361107 /$

UNICEF. (2005). Strategic Communication for Behviour and Social Change in South Asia. Available at https://www.unicef.org/cbsc/files/Strategic_Communication_for_Behaviour_and_Socia 1_Change.pdf.

Vaughan, E., \& Tinker, T. (2009). Effective Health Risk Communication About Pandemic Influenza for Vulnerable Populations. American Journal of Public Health, 99(Suppl 2), S324-S332. https://doi.org/10.2105/AJPH.2009.162537

Waterson, J. (2020, March 25). UK towns lose local newspapers as impact of coronavirus deepens. The Guardian. https:/www.theguardian.com/world/2020/mar/25/uk-townslose-local-newspapers-as-impact-of-coronavirus-deepens.

WHO. (2020, August 4). COVID-19: events as they happen. Available at https://www.who.int/emergencies/diseases/novel-coronavirus-2019/events-as-theyhappen. 
Below is the list of other keywords related to 13 selected search term over the period. (Appendix I)

Other keywords related to selected Keywords

\begin{tabular}{|c|c|c|c|c|c|}
\hline S.No & Coronavirus & Lockdown & Quarantine & Social distancing & Hand wash \\
\hline 1 & india coronavirus & india lockdown & Quarantine & social distancing meaning & hand wash dettol \\
\hline 2 & coronavirus in india & lockdown in india & Meaning & social distancing coronavirus & dettol \\
\hline 3 & coronavirus update & lockdown news & Definition & $\begin{array}{l}\text { social distancing meaning in } \\
\text { hindi }\end{array}$ & hand wash sanitizer \\
\hline 4 & coronavirus cases & coronavirus lockdown & Quarantine & social distancing quotes & hand sanitizer \\
\hline 5 & coronavirus news & corona lockdown & Quarantine & social distancing synonym & sanitizer \\
\hline 6 & corona & lockdown meaning & Home & what is social distancing & hand wash price \\
\hline 9 & coronavirus world & lockdown extended & Isolation & & dettol hand wash price \\
\hline 10 & coronavirus india cases & who & & & dettol hand sanitizer \\
\hline 11 & coronavirus symptoms & lockdown date & & & hand wash sanitizer price \\
\hline 12 & coronavirus live & who lockdown & & & handwash \\
\hline 13 & coronavirus in india cases & lockdown delhi & & & dettol sanitizer \\
\hline 18 & italy & lockdown update & & & lifebuoy hand wash \\
\hline 19 & italy coronavirus & lockdown extension & & & hand wash basin \\
\hline 20 & coronavirus news india & lockdown meaning in hindi & & & hand wash images \\
\hline 21 & $\begin{array}{l}\text { coronavirus in india } \\
\text { update }\end{array}$ & $\begin{array}{l}\text { lockdown in india } \\
\text { coronavirus }\end{array}$ & & & dettol liquid \\
\hline 22 & coronavirus in world & lockdown india extended & & & dettol liquid hand wash \\
\hline 23 & latest coronavirus news & india lockdown date & & & alcohol sanitizer \\
\hline 24 & coronavirus count & lockdown extend & & & alcohol based hand wash \\
\hline 25 & worldometer coronavirus & up lockdown & & & godrej hand wash \\
\hline
\end{tabular}




\begin{tabular}{|l|l|l|l|}
\hline S.No. & Outbreak & Epidemics & Pandemic \\
\hline 1 & coronavirus outbreak & epidemic meaning & pandemic meaning \\
\hline 2 & corona & pandemic & epidemic \\
\hline 3 & corona outbreak & pandemic meaning & epidemic pandemic \\
\hline 4 & outbreak meaning & epidemic meaning hindi & coronavirus pandemic \\
\hline 5 & corona virus & coronavirus epidemic & pandemic meaning hindi \\
\hline 6 & corona virus outbreak & epidemic in hindi & corona pandemic \\
\hline 7 & corona outbreak india & epidemic vs pandemic & epidemic meaning \\
\hline 8 & india coronavirus outbreak & corona epidemic & pandemic in hindi \\
\hline 9 & covid outbreak & epidemic and pandemic & endemic \\
\hline 10 & china outbreak & epidemic meaning in hindi & pandemic meaning in hindi \\
\hline 11 & coronavirus outbreak in india & endemic & meaning of pandemic \\
\hline 12 & covid 19 outbreak & epidemic act & epidemic and pandemic \\
\hline 13 & coronavirus in india & epidemic disease & coronavirus pandemic india \\
\hline 14 & corona outbreak in india & epidemic in india & covid 19 \\
\hline 15 & disease outbreak & epidemic and pandemic difference & covid 19 pandemic \\
\hline 16 & outbreak of coronavirus & meaning of epidemic & pandemic disease \\
\hline 17 & china virus outbreak & epidemic meaning english & who \\
\hline 18 & china virus & pandemic meaning hindi & pandemic vs endemic \\
\hline 19 & pandemic & difference between pandemic and epidemic & epidemic vs pandemic \\
\hline 20 & plague outbreak & pandemic in hindi & pandemic meaning in english \\
\hline 21 & plague & epidemic meaning in english & what is pandemic \\
\hline 22 & outbreak movie & what is epidemic & epidemic and pandemic difference \\
\hline 23 & corona virus india & epidemic diseases & corona pandemic india \\
\hline 24 & china coronavirus outbreak & pandemic meaning in hindi & difference between epidemic and pandemic \\
\hline 25 & ebola & epidemic vs pandemic meaning & coronavirus pandemic in india \\
\hline & & &
\end{tabular}




\begin{tabular}{|c|c|c|c|c|c|}
\hline S.No & Sanitizer & Covid 19 & Coronavirus testing & N95 Mask & Novel Coronavirus \\
\hline 1 & sanitizer hand & covid 19 india & india coronavirus testing & online n95 mask & novel meaning \\
\hline 2 & alcohol sanitizer & covid india & india coronavirus & mask online & novel coronavirus meaning \\
\hline 3 & sanitizer dettol & covid 19 tracker & coronavirus india & mask $\mathrm{n} 95$ price & coronavirus india \\
\hline 5 & dettol & covid 19 cases & coronavirus testing in india & n95 mask india & novel corona virus \\
\hline 6 & sanitizer price & covid 19 tracker india & coronavirus testing kit & n95 mask coronavirus & corona virus \\
\hline 7 & sanitizer online & covid 19 india cases & coronavirus testing near me & coronavirus mask & novel coronavirus in india \\
\hline 9 & dettol hand sanitizer & covid 19 india.org & coronavirus update & n95 face mask & why called novel coronavirus \\
\hline 10 & spray sanitizer & covid 19 update & testing kit for coronavirus & face mask & what is novel coronavirus \\
\hline 11 & hand sanitizer online & covid 19 news & coronavirus vaccine & $3 \mathrm{~m}$ mask & coronavirus symptoms \\
\hline 12 & how to make sanitizer & covid 19 live & corona testing near me & n95 mask $3 \mathrm{~m}$ & why is coronavirus called novel \\
\hline 13 & hand sanitizer india & $\begin{array}{l}\text { covid } 19 \text { cases in } \\
\text { india }\end{array}$ & coronavirus tips & corona mask n95 & novel coronavirus symptoms \\
\hline 17 & sanitizer alcohol based & covid 19 india live & & mask for coronavirus & coronavirus update \\
\hline 18 & lifebuoy & covid 19 org & & buy n95 mask online & covid 19 \\
\hline 19 & best sanitizer & covid 19 meaning & & n95 masks & novel coronavirus map \\
\hline 20 & himalaya sanitizer & covid 19 update india & & n95 respirator mask & novel coronavirus 2019 \\
\hline 21 & himalaya & covid full form & & n95 mask online india & meaning of novel coronavirus \\
\hline 22 & sanitizer in hindi & covid 19 full form & & n95 mask price india & novel coronavirus wiki \\
\hline 23 & mask & covid 19 vaccine & & $\begin{array}{l}\text { mask } n 95 \text { price in } \\
\text { india }\end{array}$ & novel coronavirus disease \\
\hline 24 & $\begin{array}{l}\text { hand sanitizer with } \\
\text { alcohol }\end{array}$ & who covid 19 & & corona virus mask & novel coronavirus treatment \\
\hline
\end{tabular}


